\title{
One-pot synthesis of 5-hydroxymethylfurfural from glucose using bifunctional [Sn,Al]-Beta catalysts
}

\author{
Liang Li, Jianghong Ding, Jin-Gang Jiang, Zhiguo Zhu, Peng Wu* \\ Shanghai Key Laboratory of Green Chemistry and Chemical Processes, Department of Chemistry, East China Normal University, Shanghai 200062, China
}

\section{A R T I C L E I N F O}

Article history:

Received 28 November 2014

Accepted 13 January 2015

Published 20 June 2015

\section{Keywords:}

[Sn,Al]-Beta

Aldose-Ketose Isomerization

Bifunctional Catalysis

Hydroxymethyl furfural

Biomass

Isomorphous substitution

\begin{abstract}
A B S T R A C T
The one-pot synthesis of 5-hydroxymethylfurfural (5-HMF) from glucose was investigated, using [Sn,Al]-Beta catalysts prepared by a combination of partial dealumination and isomorphous substitution of $\mathrm{Sn}$ into the zeolite framework. The amount of $\mathrm{Al}$ in $[\mathrm{Sn}, \mathrm{Al}]-\mathrm{Beta}$ was adjusted by changing the concentration and acid treatment time, and the Sn content was varied by changing the $\mathrm{SnCl}_{4}$ vapor treatment time. [Sn,Al]-Beta contains framework Al-related Brönsted acid sites and tetrahedral Sn-related Lewis acid sites, and is therefore a bifunctional solid acid catalyst. The reaction parameters for the [Sn,Al]-Beta-catalyzed one-pot conversion of glucose to 5-HMF were optimized. [Sn,Al]-Beta with a suitable $\mathrm{Sn} / \mathrm{Al}$ molar ratio gave a glucose conversion of $60.0 \%$ and 5 -HMF selectivity of $62.1 \%$.
\end{abstract}

(C) 2015, Dalian Institute of Chemical Physics, Chinese Academy of Sciences. Published by Elsevier B.V. All rights reserved.

plications in the syntheses of many useful compounds and novel polymer materials, including medicines, plastic resins, and diesel fuel additives [9], through hydrogenation, oxydehydrogenation, esterification, halogenation, polymerization, hydrolysis, and other chemical reactions. Biomass hydrolysis is the main method for synthesizing 5-HMF, because it is a widely available raw material and cheap. 5-HMF is therefore a potential new platform compound based on biomass resources. In addition, levulinic acid (LA), another important platform compound, can be obtained by dehydration of 5-HMF, and can be used to synthesize more useful compounds and fuel additives via esterification, halogenation, oxidation, hydrogenation, and condensation.

However, there are numerous differences between the raw materials used, and the reaction paths and reaction intermediates involved, in the cases of traditional petrochemicals and

\footnotetext{
* Corresponding author. Tel/Fax: +86-21-62232292; E-mail: pwu@chem.ecnu.edu.cn This work was supported by the National Natural Science Foundation of China (21373089, U1162102), Ph.D. Programs Foundation of Ministry of Education (2012007613000), the National Key Technology R\&D Program (2012BAE05B02), and the Shanghai Leading Academic Discipline Project (B409).
} DOI: 10.1016/S1872-2067(14)60287-4 | http://www.sciencedirect.com/science/journal/18722067 | Chin. J. Catal., Vol. 36, No. 6, June 2015 
biomass sources such as cellulose and polysaccharides. There are both challenges and opportunities in the development of new catalysts and technological processes, and there are numerous basic issues related to catalyst design [10]. Because various functional groups coexist in biomass-based multiplatform chemicals, they are convenient for follow-up development and use, but have complex reaction paths and side reactions. It is therefore important to improve reaction conversion and selectivity through suitable catalyst design [11].

Takagaki et al. [12] used a combination of Amberlyst-15 (a solid acid) and Mg-Al hydrotalcite (a solid base) in $N, N$-dimethylformamide (DMF) for synthesizing 5-HMF from glucose; they achieved 5-HMF selectivity of 58\% and glucose conversion of $73 \%$ at $453 \mathrm{~K}$. Zhao et al. [13] demonstrated that the use of $\mathrm{CrCl}_{2}$ in 1-ethyl-3-methylimidazolium chloride [EMIM]Cl gave 5-HMF selectivity of $72 \%$ and glucose conversion of $94 \%$ at $353 \mathrm{~K}$. Huang et al. [14] showed that combining enzymatic and acid catalysts to synthesize 5-HMF from glucose gave $5-\mathrm{HMF}$ selectivity of $70 \%$ and glucose conversion of $85 \%$. Otomo et al. [15] used dealuminated Beta-zeolite as an effective bifunctional catalyst for the direct transformation of glucose to 5 -HMF; they achieved 55\% selectivity for 5-HMF and 78\% glucose conversion.

Glucose, an abundant monosaccharide obtained by depolymerization of cellulose, can be converted to 5-HMF. The reaction involves two steps: (1) isomerization of glucose to fructose, and (2) dehydration of fructose to 5-HMF. Previous studies of 5-HMF synthesis from glucose, some of which were outlined above, had several disadvantages, because they used systems that involved enzymes, numerous reactors, or environmentally unfriendly catalysts and solvents. For example, one-pot, ionic-liquid systems suffer from high separation costs, sensitivity to reaction conditions, and undesirable environmental effects. The one-pot synthesis of 5-HMF from glucose in aqueous media, with high efficiency, is still a challenge. Here, we report an efficient one-pot synthesis of 5-HMF from sugars using $\mathrm{Sn}, \mathrm{Al}$-containing silica molecular sieves with the Beta-zeolite topology in concert with acid catalysts.

Beta-zeolites, with large pore diameters and crossing 12-MR channels, have been successfully used in applications such as catalytic cracking, isomerization, alkylation, alkyl transfer reactions, petrochemical processes, and adsorption. The implantation of heteroatoms into Beta-zeolites has become an important part of zeolite research in recent years. Sn-Beta can catalyze the chemoselective Baeyer-Villiger oxidation of ketones or aldehydes with $\mathrm{H}_{2} \mathrm{O}_{2}$ by directly activating the carbonyl groups [16-18]. Both Sn-Beta and Zr-Beta are efficient catalysts for the Meerwein-Ponndorf-Verley reduction of ketones with alcohols $[19,20]$. Davis et al. [21] achieved one-pot synthesis of 5-HMF from glucose with $79 \%$ conversion and $72 \%$ selectivity by combining a heterogeneous Sn-Beta catalyst and a homogeneous $\mathrm{HCl}$ catalyst and using a biphasic water/tetrahydrofuran reaction system. Cleaner routes are expected to be developed by designing novel heterogeneous catalysts with multifunctionalities.

[Sn,Al]-Beta has been synthesized using various methods. Hammond et al. [22] prepared the catalyst by simply grinding the appropriate amount of tin(II) acetate with the required amount of dealuminated zeolite, and achieved high activity in the conversion of dihydroxyacetone to ethyl lactate. Dijkmans et al. [23] prepared [Sn,Al]-Beta using a grafting method; deAl-Beta and $\mathrm{SnCl}_{4} \cdot 5 \mathrm{H}_{2} \mathrm{O}$ were suspended in isopropanol and refluxed under $\mathrm{N}_{2}$, giving a fructose yield of $41 \%$. Liu et al. [8] treated a highly dealuminated Beta-zeolite with $\mathrm{SnCl}_{4}$ vapor, and obtained a fructose yield of $46 \%$. All these studies focused on highly dealuminated Beta-zeolites, and analysis of glucose to fructose conversion.

In this study, [Sn,Al]-Beta was prepared from partially dealuminated $\mathrm{H}$-Al-Beta and $\mathrm{SnCl}_{4}$ vapor through solid-gas isomorphous substitution, giving rise to a bifunctional catalyst with both Brönsted and Lewis acid sites. The $\mathrm{Al}$ and Sn contents of [Sn,Al]-Beta were both adjusted by changing the dealumination and $\mathrm{SnCl}_{4}$ treatment conditions. The catalytic properties of [Sn,Al]-Beta were investigated in the one-pot synthesis of 5 -HMF by direct conversion of glucose.

\section{Experimental}

\subsection{Chemicals}

Glucose (99.5\%), fructose (99.5\%), 5-HMF (99\%), FA (99.5\%) and LA (99.5\%) were purchased from Sinopharm Chemical Reagent Co., Ltd. Beta zeolite was purchased from Sinopec. It was used as starting maerial for preparing dealuminated Beta zeolite.

\subsection{Synthesis of various ${ }^{*} B E A$-type metallosilicates}

As shown in Scheme 1, a Sn- and Al-containing Beta-zeolite, [Sn,Al]-Beta, was prepared by secondary isomorphous substitution of Sn into the framework of a partially dealuminated Beta-zeolite through a gas-solid reaction using $\mathrm{SnCl}_{4}$ vapor [18]. A commercial H-Al-Beta-aluminosilicate with nanosized crystals (Sinopec, Si/Al atomic ratio 10) was treated in $\mathrm{HNO}_{3}$ solutions of various concentrations, at a solid-to-liquid ratio of $1 \mathrm{~g}: 50 \mathrm{~mL}$, under either room temperature or reflux conditions, for a certain period of time (Table 1).

The treated samples were collected by centrifugation, washed repeatedly with deionized water until the $\mathrm{pH}$ was $c a .7$, and dried at $353 \mathrm{~K}$ overnight, resulting in a series of partially dealuminated zeolites, denoted by $\operatorname{De}-\operatorname{Al}-\operatorname{Beta}(x)$, where $x$ is the $\mathrm{Si} / \mathrm{Al}$ molar ratio. In a typical treatment with $\mathrm{SnCl}_{4}$, $\operatorname{De}-\operatorname{Al}-\operatorname{Beta}(x)(2 \mathrm{~g})$ was pretreated in a quartz tubular reactor

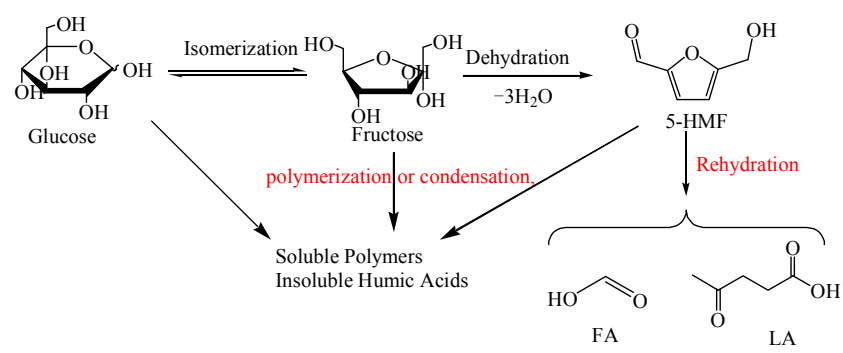

Scheme 1. One-pot synthesis of 5-HMF from glucose on [Sn,Al]-Beta catalyst. 
Table 1

Dealumination of H-Al-Beta-aluminosilicate.

\begin{tabular}{lccccc}
\hline No. & $\mathrm{HNO}_{3}(\mathrm{~mol} / \mathrm{L})$ & Temperature & Time $(\mathrm{h})$ & $\mathrm{Si} / \mathrm{Al}$ ratio & \\
\hline 1 & 1 & RT & R.C. $^{\mathrm{b}}(\%)$ \\
2 & 3 & RT & 6 & 35 & 100 \\
3 & 6 & RT & 6 & 60 & 99 \\
4 & 1 & RT & 12 & 91 & 98 \\
5 & 3 & RT & 12 & 41 & 100 \\
6 & 6 & RT & 12 & 70 & 99 \\
7 & 1 & RT & 18 & 99 & 98 \\
8 & 3 & RT & 18 & 50 & 100 \\
9 & 6 & RT & 18 & 111 & 92 \\
10 & 1 & Reflux & 3 & 81 & 100 \\
11 & 2 & Reflux & 3 & 111 & 99 \\
12 & 3 & Reflux & 3 & 174 & 99 \\
13 & 4 & Reflux & 3 & 215 & 98 \\
14 & 13 & Reflux & 8 & 1685 & 97 \\
\hline
\end{tabular}

a Determined by ICP analysis.

b Relative crystallinity measured by XRD.

at $773 \mathrm{~K}$ for $2 \mathrm{~h}$ under a stream of dry $\mathrm{N}_{2}$. The reactor temperature was raised to $673 \mathrm{~K}$, and the $\mathrm{N}_{2}$ flow was diverted through anhydrous liquid $\mathrm{SnCl}_{4}$ in a glass bubbler. The $\mathrm{SnCl}_{4}$ vapor was carried by the $\mathrm{N}_{2}$ flow and contacted the zeolite bed for a predetermined time period ( $2 \mathrm{~min}$ to $2 \mathrm{~h}$ ). After the treatment, the sample was purged with pure $\mathrm{N}_{2}$ at the same temperature for $1 \mathrm{~h}$ to remove any residual $\mathrm{SnCl}_{4}$ from the zeolite powder. After cooling to room temperature in $\mathrm{N}_{2}$, the treated zeolite was washed with deionized water under stirring until chloride ions were not detected in the filtrate by $\mathrm{AgNO}_{3}$ solution, and then dried in air at $363 \mathrm{~K}$ overnight. The product is denoted by $[\mathrm{Sn}, \mathrm{Al}]-\operatorname{Beta}(x)$, where $x$ represents the $\mathrm{Si} / \mathrm{Al}$ molar ratio of the parent zeolite before treatment with $\mathrm{SnCl}_{4}$. $[\mathrm{Ti}, \mathrm{Al}]$-Beta catalysts were prepared by a similar method, using $\mathrm{TiCl}_{4}$.

For control experiments, [Sn,Al]-Beta-L catalysts were synthesized by liquid-phase incorporation, using literature procedures [20]. In a typical synthesis, $\mathrm{HNO}_{3}(0.18 \mathrm{~g}, 65 \mathrm{wt} \%)$ and $\mathrm{NH}_{4} \mathrm{~F}(0.44 \mathrm{~g}, 96 \mathrm{wt} \%)$ were dissolved in deionized water (60 g) at room temperature. After stirring for $10 \mathrm{~min}, \mathrm{SnCl}_{4} \cdot 5 \mathrm{H}_{2} \mathrm{O}$ $(0.59 \mathrm{~g})$ was slowly added to the solution, and the mixture was stirred for $10 \mathrm{~min}$. The solution was then seeded with $\operatorname{De}-\operatorname{Al}-\operatorname{Beta}(x)$ (0.6 g) and stirred at $308 \mathrm{~K}$ for $5 \mathrm{~h}$. After cooling to room temperature, the treated zeolite was washed with deionized water under stirring until chloride ions were not detected in the filtrate by $\mathrm{AgNO}_{3}$ solution, and then dried in air at $363 \mathrm{~K}$ overnight. The product is denoted by [Sn,Al]-Beta $(x)-\mathrm{L}$, where $x$ represents the $\mathrm{Si} / \mathrm{Al}$ molar ratio of the parent zeolite before liquid-phase post-insertion of Sn.

For control experiments, Sn-Beta-HTS zeolites were synthesized directly, using the procedure reported in the literature $[16,18]$. The synthesis was performed in a fluoride system, using $\mathrm{SnCl}_{4} \cdot 5 \mathrm{H}_{2} \mathrm{O}$ as the $\mathrm{Sn}$ source and with the addition of dealuminated Beta-zeolite as seeds. The synthetic gel had a composition of $1.0 \mathrm{SiO}_{2}: 0.005 \mathrm{SnCl}_{4}: 0.56$ tetraethylammonium hydroxide:0.54 HF:7.5 $\mathrm{H}_{2} \mathrm{O}$. Crystallization was performed in a Teflon-lined stainless-steel autoclave under static conditions at $413 \mathrm{~K}$ for $7 \mathrm{~d}$. The solids were recovered by filtration, exten- sively washed with water, dried at $373 \mathrm{~K}$ overnight, and calcined at $853 \mathrm{~K}$ for $6 \mathrm{~h}$ to obtain Sn-Beta-HTS.

\subsection{Characterization}

Powder X-ray diffraction (XRD) patterns were obtained using a Rigaku Ultima IV X-ray diffractometer, with $\mathrm{Cu}-K_{\alpha}$ radiation $(\lambda=0.15405 \mathrm{~nm})$. The $\mathrm{Sn}$ and $\mathrm{Al}$ contents were determined by inductively coupled plasma atomic emission spectroscopy (ICP-AES), using a Thermo IRIS Intrepid II XSP atomic emission spectrometer. The specific surface areas were determined by $\mathrm{N}_{2}$ adsorption-desorption at $77 \mathrm{~K}$, using a BELSORPMAX instrument, after activating the sample at $573 \mathrm{~K}$ under vacuum for at least $10 \mathrm{~h}$. Ultraviolet-visible (UV-vis) diffuse reflectance spectra were recorded with a Shimadzu UV-2550 spectrophotometer, using $\mathrm{BaSO}_{4}$ as a reference. Fourier transform infrared (FT-IR) spectra were recorded using a Nicolet Nexus 670 FT-IR spectrometer in absorbance mode at a spectral resolution of 2 $\mathrm{cm}^{-1}$. The sample was pressed into a self-supported wafer of thickness $4.8 \mathrm{mg} \mathrm{cm}^{-2}$. The wafer was set in a quartz IR cell, which was sealed with $\mathrm{CaF}_{2}$ windows and connected to a vacuum system. The sample was evacuated at $723 \mathrm{~K}$ for $2 \mathrm{~h}$. Pyridine adsorption was performed by exposing the pretreated wafer to pyridine vapor at $298 \mathrm{~K}$ for $0.5 \mathrm{~h}$. The adsorbed pyridine was successively desorbed at different temperatures (423-723 K) for $1 \mathrm{~h}$. All the spectra were collected at room temperature. ${ }^{27} \mathrm{Al}$ and ${ }^{119} \mathrm{Sn}$ magic-angle-spinning nuclear magnetic resonance (MAS/NMR) spectra were obtained using a Varian VNMRS 400WB NMR spectrometer.

\subsection{Catalytic reaction}

The catalytic tests were performed in an autoclave containing a 25-mL PTFE lining and immersed in a thermostated oil-bath. The reaction mixture typically contained glucose aqueous solution ( $2.5 \mathrm{~g}, 10 \mathrm{wt} \%)$, catalyst (50 mg), and dimethyl sulfoxide (DMSO; $6 \mathrm{~mL}$ ). The mixture was stirred vigorously at $433 \mathrm{~K}$ for $30 \mathrm{~min}$ to $5 \mathrm{~h}$. The reaction mixture was analyzed using gas chromatography (GC; Shimadzu GC-14B) and high-performance liquid chromatography (HPLC) to determine the conversion and product selectivity. 5-HMF, LA, and formic acid (FA) were determined using GC (GC-14B, FAAP capillary column) and quantified using phenol as an internal standard. HPLC was performed using a Waters 2695 system equipped with a photodiode array detector (960 UV, $280 \mathrm{~nm}$ ) and R2414 refractive index detectors. The disappearances of glucose and fructose were monitored with an Aminex HPX-87H column, using 75:25 $\mathrm{v} / \mathrm{v}$ acetonitrile:water at a flow rate of $1 \mathrm{~mL} \mathrm{~min}-1$ and a column temperature of $298 \mathrm{~K}$.

\section{Results and discussion}

\subsection{Catalyst preparation and characterization}

Figure 1 shows the XRD patterns of H-Al-Beta, De-Al-Beta(100), and [Sn,Al]-Beta(100). The samples exhibited well-defined reflections, because of the *BEA topology. The 


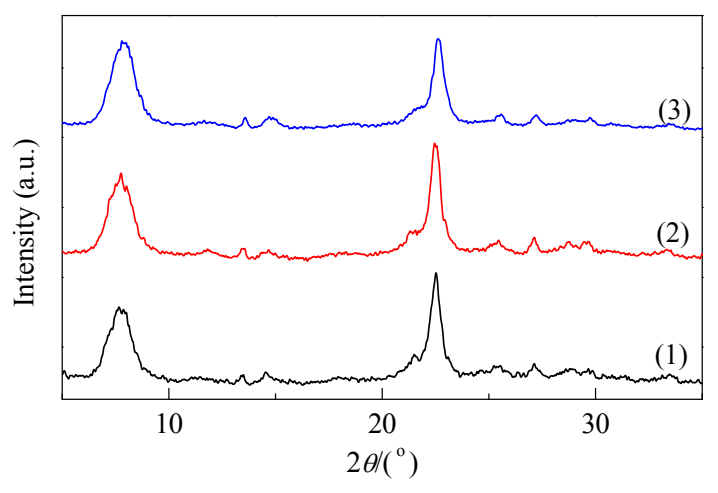

Fig. 1. XRD patterns of H-Al-Beta (1), De-Al-Beta(100) (2), and [Sn,Al]-Beta(100) (3).

patterns had comparable diffraction intensities, indicating that no collapse of the crystalline structure occurred during dealumination or $\mathrm{SnCl}_{4}$ vapor treatment.

UV-vis spectroscopy is a sensitive and convenient tool, and is widely used to detect the coordination states of transition-metal ions in zeolites, particularly $\mathrm{Ti}-, \mathrm{Sn}-$, or $\mathrm{Zr}$-containing metallosilicates. Figure 2 shows the UV-vis spectra of the [Sn,Al]-Beta samples with different Sn loadings prepared by $\mathrm{SnCl}_{4}$ vapor treatment at $773 \mathrm{~K}$ for different periods of time ([Sn,Al]-Beta(100)-L sample was prepared by liquid-phase insertion of Sn). The main absorption band, at $220 \mathrm{~nm}$, is characteristic of tetrahedrally coordinated $\mathrm{Sn}$ species in framework positions. A weak shoulder band at $255 \mathrm{~nm}$ was also observed for the [Sn,Al]-Beta samples containing relatively high $\mathrm{Sn}$ contents. This implies the presence of some extra-framework Sn species; this is consistent with the results reported for microporous Sn-MFI [25]. The $220 \mathrm{~nm}$ band increased in intensity monotonically with increasing amount of Sn, suggesting that most of the Sn ions were incorporated into the framework, although diffuse reflectance spectra are not completely reliable for quantification. However, a clear shoulder band at $255 \mathrm{~nm}$ was observed for the [Sn,Al]-Beta-L sample, prepared by liquid-phase Sn incorporation, indicating that it contained a substantial number of extra-framework $\mathrm{Sn}$ species. In subsequent

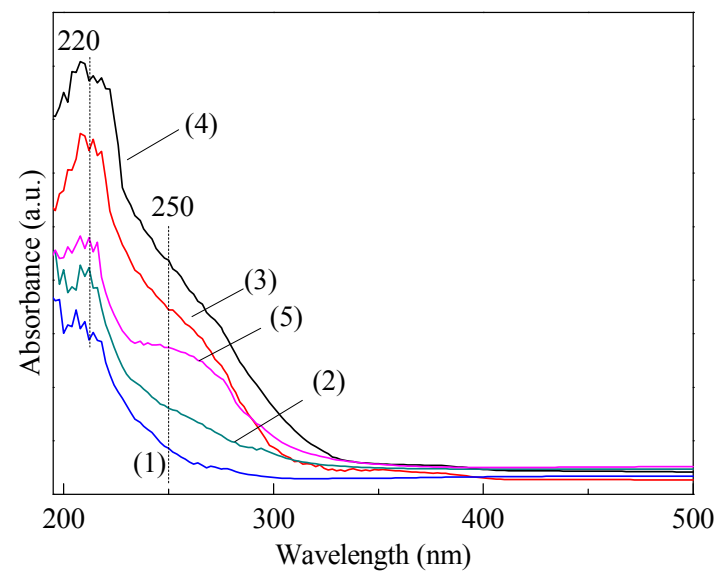

Fig. 2. UV-vis spectra of [Sn,Al]-Beta(100) prepared by $\mathrm{SnCl}_{4}$ treatment

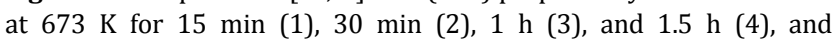
[Sn,Al]-Beta(100)-L (5). experiments, these extra-framework Sn species were easily detached after calcination; this is unfavorable for catalytic reactions.

${ }^{119}$ Sn MAS NMR spectra provided strong proof for the incorporation of tetrahedral $\mathrm{Sn}$ species by $\mathrm{SnCl}_{4}$ treatment. In contrast to the sharp resonance at -604 ppm observed for pure $\mathrm{SnO}_{2}$, hydrated [Sn,Al]-Beta(100) showed a very broad signal centered at $\delta=-720$ (Fig. 3(a)). The resonances in the range $\delta=$ -690 to $\delta=-740$ are generally attributed to the Sn(IV) species and water adsorption [26]. Dehydration shifts the resonance to $\delta=-450$ (Fig. 3(a)), which is characteristic of tetrahedrally coordinated framework Sn species. These results, which agree with those reported for directly synthesized Sn-Beta [26], rule out the presence of octahedral $\mathrm{SnO}_{2}$ in $[\mathrm{Sn}, \mathrm{Al}]-\mathrm{Beta}(100)$ and verify that the incorporated Sn species are mainly located in the framework.

The resonances at $\delta=50-60$ in the ${ }^{27} \mathrm{Al}$ MAS NMR spectra correspond to tetrahedrally coordinated Al species incorporated in the zeolite framework. Extra-framework Al species present as pentahedrally and octahedrally coordinated species give resonances at 30 and $0 \mathrm{ppm}$, respectively. The resonance at $\delta=50-60$ observed for [Sn,Al]-Beta(100) (Fig. 3(b)) shows that the residual $\mathrm{Al}$ species in $[\mathrm{Sn}, \mathrm{Al}]-\mathrm{Beta}(100)$ after the solid-gas reaction were mainly located in the framework.

\subsection{Sn incorporation mechanism}

The results described above suggest that the formation of tetrahedral $\mathrm{Sn}$ species took place via routes other than isomorphous substitution of thermodynamically stable framework Si ions. The Sn ions were probably incorporated through the reaction of $\mathrm{SnCl}_{4}$ molecules with internal silanols. IR and NMR spectroscopies were used to study this issue. The IR spectra in the hydroxyl stretching vibration regions of H-Al-Beta, De-Al-Beta, [Sn,Al]-Beta, and Sn-Beta are shown in Fig. 4. The spectra were recorded in absorbance mode using self-supported wafers after complete dehydration under vac-
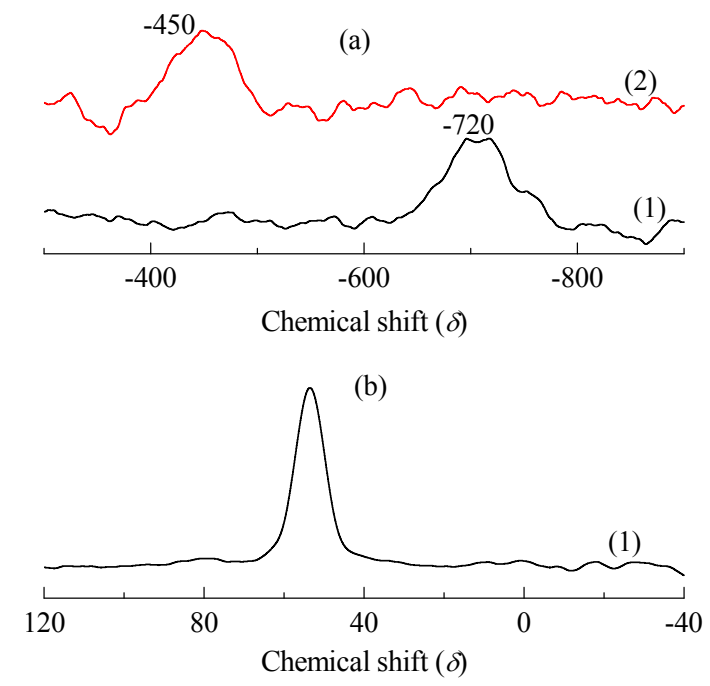

Fig. 3. ${ }^{119} \mathrm{Sn}$ MAS NMR spectra (a) and ${ }^{27} \mathrm{Al}$ MAS NMR spectrum (b) of [Sn,Al]-Beta(100) in hydrated form (1) and after dehydration at $673 \mathrm{~K}$ (2). 


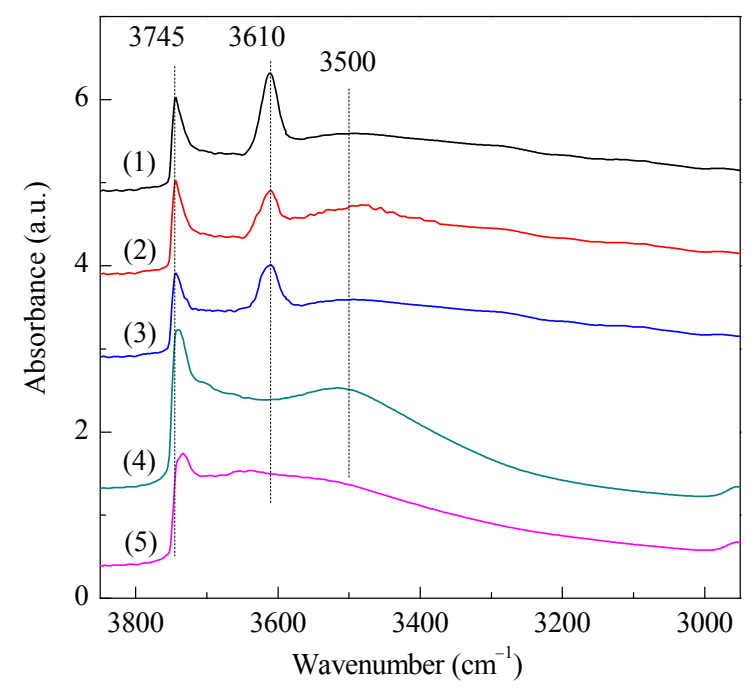

Fig. 4. FT-IR spectra in hydroxyl stretching vibration region of H-Al-Beta (1), De-Al-Beta(100) (2), [Sn,Al]-Beta(100) (3), De-Al-Beta(1700) (4), and [Sn,Al]-Beta(1700) (5).

uum; this eliminated contamination by physically or chemically adsorbed $\mathrm{H}_{2} \mathrm{O}$ [27]. The parent H-Al-Beta sample had two bands, at 3745 and $3610 \mathrm{~cm}^{-1}$, which are assigned to terminal silanol groups and structural $\mathrm{Si}(\mathrm{OH}) \mathrm{Al}$ groups, respectively [28]. However, without dealumination, a much broader band at $3500 \mathrm{~cm}^{-1}$ was observed, attributed to delocalized hydrogen-bonded internal silanols. These silanols are mainly generated from stacking faults in the Beta polymorphs. Extensive dealumination caused complete disappearance of the 3610 $\mathrm{cm}^{-1}$ band, and this band was weakened by mild dealumina- tion. This is in accordance with the ICP-AES results, shown in Table 1, which verify that De-Al-Beta was highly siliceous. Dealumination significantly enhanced the bands at 3745 and $3500 \mathrm{~cm}^{-1}$. This is clear evidence for the formation of defect sites on the external surface and inside the framework. The hydroxyl groups in the framework are believed to be clustered as hydroxyl nests, as reported in previous dealumination/realumination studies [25]. After the $\mathrm{SnCl}_{4}$ vapor treatment at $773 \mathrm{~K}$ for $1 \mathrm{~h}$, the $3745 \mathrm{~cm}^{-1}$ band decreased slightly in intensity, indicating that the $\mathrm{SnCl}_{4}$ molecules interacted with the terminal silanols to a certain extent. This reaction probably generated some of the extra-framework Sn species in post-synthesize process, shown in the UV-vis spectra (Fig. 3). More importantly, the $3500 \mathrm{~cm}^{-1}$ band decreased greatly in intensity after the $\mathrm{SnCl}_{4}$ vapor treatment. This indicates a reaction between $\mathrm{SnCl}_{4}$ molecules and internal silanols, implying that the incorporation of $\mathrm{Sn}$ atoms into the framework sites took place in the same manner as alumination or titanation of highly siliceous MOR zeolites [28,29].

\subsection{Acidic properties of [Sn,Al]-Beta zeolites}

The catalytic properties of Sn-zeolites are closely related to their Lewis acidities. Pyridine was used as a probe molecule to provide detailed information on the amounts and strengths of Lewis acid sites in [Sn,Al]-Beta. The IR spectra of adsorbed pyridine in the range of pyridine-ring-stretching modes were recorded after desorption at various temperatures (Fig. 5). As can be seen from Fig. 5(b), De-Al-Beta(1700) showed the stretching mode vibrations of hydrogen-bonded (hb) and physically (ph) adsorbed pyridine at 1599 (hb, mode 8a), 1581

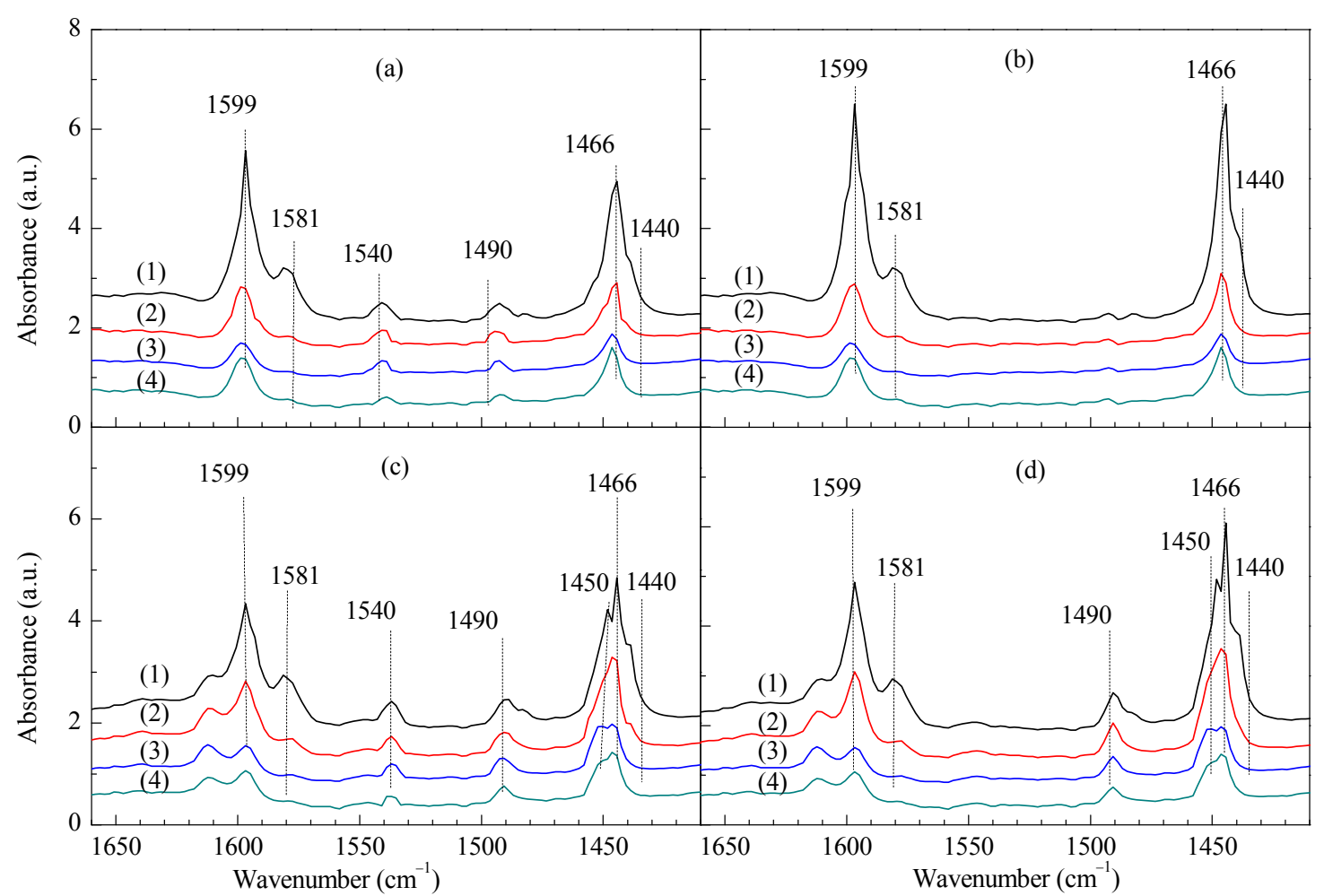

Fig. 5. IR spectra of De-Al-Beta(100) (a), De-Al-Beta(1700) (b), [Sn,Al]-Beta(100) (c), and [Sn,Al]-Beta(1700) (d) after pyridine adsorption at $298 \mathrm{~K}$ for $30 \mathrm{~min}$ and desorption at $423 \mathrm{~K}(1), 523 \mathrm{~K}(2), 623 \mathrm{~K}(3)$, and $723 \mathrm{~K}(4)$ for $1 \mathrm{~h}$. 
(hb, ph, mode 8b), 1483 (ph, mode 19a), 1446 (hb, mode 19b), and 1440 (ph, mode 19b) $\mathrm{cm}^{-1}$ [30-32]. The bands at 1483 and $1440 \mathrm{~cm}^{-1}$, which are associated with physically adsorbed pyridine, disappeared after desorption at $523 \mathrm{~K}$. The bands at 1599 and $1446 \mathrm{~cm}^{-1}$, which are associated with hydrogen-bonded pyridine, were more resistant against evacuation, but decreased in intensity with increasing desorption temperature. In contrast, the bands at $1490 \mathrm{~cm}^{-1}$, which are characteristic of both Brönsted and Lewis acid sites, and at $1450 \mathrm{~cm}^{-1}$, corresponding to Lewis acid sites, were absent in the spectra of De-Al-Beta(1700), regardless of the desorption temperature, suggesting that De-Al-Beta(1700) was almost free of Lewis acid sites. In the spectra of [Sn,Al]-Beta(1700), which has a relatively high Sn content, we observed two distinct bands, at 1611 and $1490 \mathrm{~cm}^{-1}$, and a shoulder at $1450 \mathrm{~cm}^{-1}$, in addition to bands similar to those shown by De-Al-Beta(1700) (Fig. 5(d)). These new bands, which are absent for De-Al-Beta(1700), were evacuation temperature resistant and remained even after desorption at $723 \mathrm{~K}$ (Fig. 5(d)). The bands at 1611, 1490, and 1450 $\mathrm{cm}^{-1}$ correlated with different vibration modes of the pyridine rings adsorbed on Sn species incorporated into the Beta-zeolite matrix [32-34]. A $\mathrm{C}_{5} \mathrm{H}_{5} \mathrm{~N} \cdots \mathrm{Sn}(\mathrm{IV})$ adduct with a pyridine molecule (ligand) coordinated to the Sn(IV) ion (center) may contribute to these bands. These three bands can be taken as evidence for the presence of Lewis acid sites in [Sn,Al]-Beta(1700). However, the spectra did not have a clear band at $1540 \mathrm{~cm}^{-1}$ from the vibrations of pyridinium ions, which is commonly used as evidence for the presence of Brönsted acid sites. [Sn,Al]-Beta(1700) therefore had Lewis acidity rather than Brönsted acidity.

Bands at $1490 \mathrm{~cm}^{-1}$ characteristic of both Brönsted and Lewis acid sites, and at $1540 \mathrm{~cm}^{-1}$, corresponding to Brönsted acid sites, were observed in the spectra of De-Al-Beta(100), regardless of the desorption temperature (Fig. 5(a)). This suggests that De-Al-Beta(100) still contained Brönsted acid sites. In the spectra of [Sn,Al]-Beta(100), these bands characteristic of Brönsted acid sites remained, and new bands characteristic of Lewis acid sites appeared (Fig. 5(c)). These results indicate that [Sn,Al]-Beta contained both Brönsted and Lewis acid sites.
Table 2

Comparison of conversions of glucose to 5-HMF over various catalysts.

\begin{tabular}{|c|c|c|c|c|}
\hline Entry & Catalyst & $\mathrm{Si} / \mathrm{Sn}$ ratio $^{\mathrm{a}}$ & $\mathrm{Si} / \mathrm{AL}$ ratio ${ }^{\mathrm{a}}$ & HMF yield (\%) \\
\hline 1 & None & - & - & 10.3 \\
\hline 2 & H-Al-Beta & $\infty$ & 9.8 & 11.3 \\
\hline 3 & {$[\mathrm{Sn}, \mathrm{Al}]-\mathrm{Beta}(50)$} & 38 & 52 & 31.4 \\
\hline 4 & {$[\mathrm{Sn}, \mathrm{Al}]-\operatorname{Beta}(100)$} & 36 & 107 & 37.3 \\
\hline 5 & {$[\mathrm{Sn}, \mathrm{Al}]-\mathrm{Beta}(100)-\mathrm{cal}$} & 38 & 110 & 37.1 \\
\hline 6 & {$[\mathrm{Sn}, \mathrm{Al}]-\operatorname{Beta}(1700)$} & 30 & 1711 & 28.3 \\
\hline 7 & {$[\mathrm{Sn}, \mathrm{Al}]-\mathrm{Beta}(50)-\mathrm{L}$} & 25 & 56 & 37.5 \\
\hline 8 & {$[\mathrm{Sn}, \mathrm{Al}]-\mathrm{Beta}(50)-\mathrm{L}-\mathrm{cal}$} & 50 & 58 & 22.1 \\
\hline 9 & Sn-Beta(200)-HTS & 206 & $\infty$ & 12.3 \\
\hline 10 & {$[\mathrm{Ti}, \mathrm{Al}]-\operatorname{Beta}(50)$} & $40^{b}$ & 61 & 18.0 \\
\hline 11 & {$[\mathrm{Ti}, \mathrm{Al}]-\mathrm{Beta}(100)$} & $34^{b}$ & 126 & 14.1 \\
\hline
\end{tabular}

Reaction conditions: catalyst $0.05 \mathrm{~g}, 10 \mathrm{wt} \%$ glucose solution $2 \mathrm{~mL}$, DMSO $6 \mathrm{~mL}, 433 \mathrm{~K}, 4 \mathrm{~h}$.

a Determined by ICP analysis.

bSi/Ti molar ratio.

\subsection{Catalytic properties of [Sn,Al]-Beta}

A combined catalyst ( $\mathrm{Sn}$-Beta and $\mathrm{HCl}$ ) has already been shown to convert glucose to 5-HMF at $\mathrm{pH}$ near 1 and in saturated aqueous salt solutions [21]. Scheme 1 shows a typical reaction pathway for glucose transformation to 5-HMF. The [Sn,Al]-Beta catalyst gave high 5-HMF yields under the same reaction conditions (Table 2, entries 3 and 4). In contrast, Al-free Sn-Beta-HTS and [Sn,Al]-Beta(1700) were less effective for 5-HMF production (Table 2, entries 6 and 9). This is because both $\mathrm{Sn}$ and $\mathrm{Al}$ atoms are required to convert glucose to 5-HMF; Sn atoms are necessary for the isomerization of glucose to fructose, and $\mathrm{Al}$ is needed for the dehydration of fructose to 5-HMF (Scheme 1). Compared with [Sn,Al]-Beta-L, which was synthesized by liquid-phase $\mathrm{Sn}$ incorporation, [Sn,Al]-Beta prepared by a solid-gas reaction gave more stable 5-HMF yields after calcination (Table 2, entries 4, 5, 7, and 8). These results verify that the Sn species incorporated by a solid-gas reaction were mainly located in the framework.

As shown in Fig. 6(a), the 5-HMF yield increased with increasing reaction temperature in the range 353-433 K. Figure
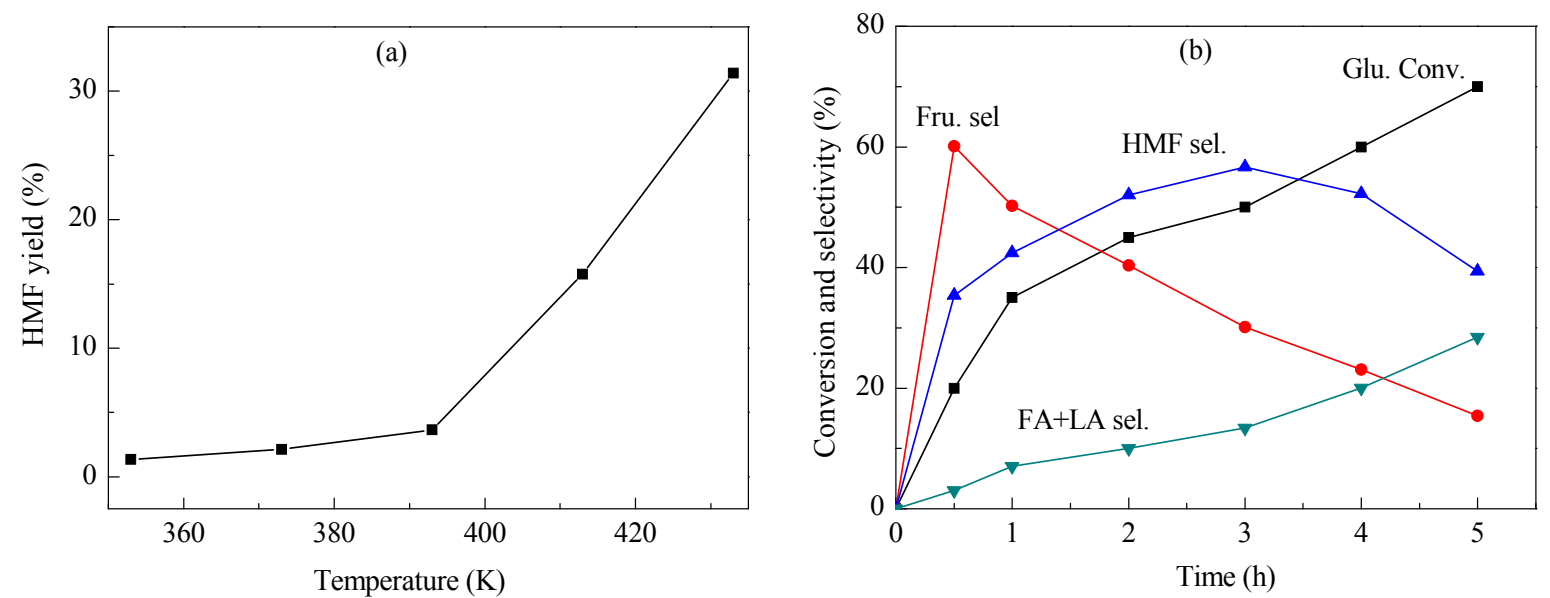

Fig. 6. Effects of reaction temperature on 5-HMF yield (a) and of reaction time on product distribution (b) in glucose conversion over [Sn,Al]-Beta(50) $(\mathrm{Si} / \mathrm{Sn}$ molar ratio $=38$, Si $/$ Al molar ratio $=52$ ). Reaction conditions: catalyst $0.05 \mathrm{~g}, 10 \mathrm{wt} \%$ glucose solution $2 \mathrm{~mL}$, DMSO $6 \mathrm{~mL}, 4 \mathrm{~h}$ or $433 \mathrm{~K}$. 


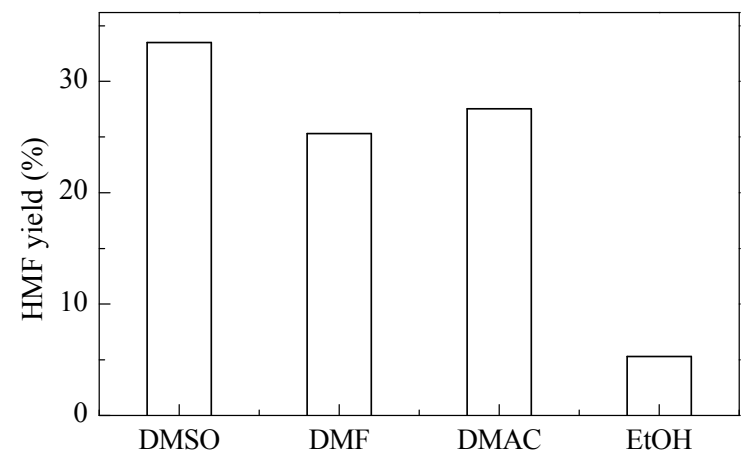

Fig. 7. Effect of solvent on yield of 5-HMF in glucose conversion over $[\mathrm{Sn}, \mathrm{Al}]-\mathrm{Beta}(50)(\mathrm{Si} / \mathrm{Sn}$ molar ratio $=38, \mathrm{Si} / \mathrm{Al}$ molar ratio $=52)$. Reaction conditions: catalyst $0.05 \mathrm{~g}, 10 \mathrm{wt} \%$ glucose solution $2 \mathrm{~mL}$, solvent 6 $\mathrm{mL}, 433 \mathrm{~K}, 4 \mathrm{~h}$.

6(b) shows the dependences of glucose conversion and 5-HMF/fructose/LA and FA selectivities on the reaction time for glucose dehydration with [Sn,Al]-Beta(50). The 5-HMF selectivity reached a maximum value of $c a .60 \%$ at $3 \mathrm{~h}$, and then decreased with time, because 5-HMF was converted to LA and FA via further dehydration. The LA and FA selectivities increased relatively rapidly after $3 \mathrm{~h}$. The fructose selectivity decreased from $0.5 \mathrm{~h}$ to $5 \mathrm{~h}$, implying a typical consecutive reaction mechanism. In view of these results, we selected $433 \mathrm{~K}$ and $4 \mathrm{~h}$ as the optimum conditions.

The effect of an organic solvent on the 5-HMF yield was examined using [Sn,Al]-Beta(50) as the catalyst. A number of solvents such as polar aprotic solvents, e.g., DMF, $N, N$-dimethylacetamide, DMSO, and a polar protic solvent (ethanol) were tested. Figure 7 shows that the highest 5-HMF yield (32\%) was achieved using DMSO at $433 \mathrm{~K}$ for $4 \mathrm{~h}$. Previous studies showed that DMSO plays a positive role in the uncatalyzed dehydration of carbohydrates; it protects (1) fructose from reactions other than dehydration to 5-HMF and (2) 5 -HMF from rehydration and humin-forming reactions $[15,35,36]$. Our results were consistent with those previously

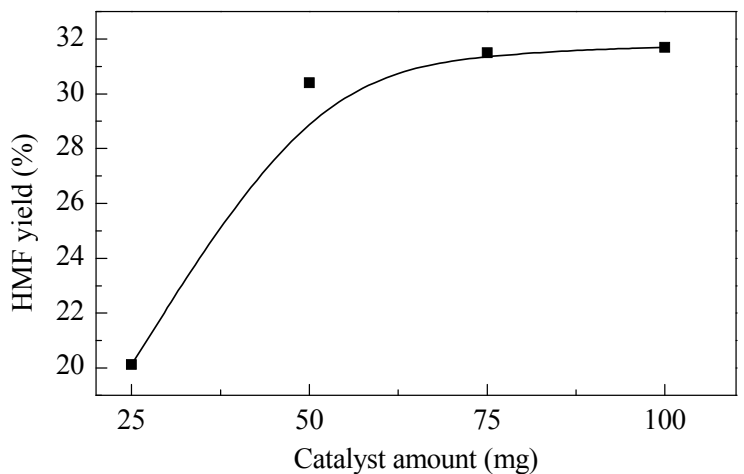

Fig. 8. Dependence of 5-HMF yield on catalyst amount in glucose conversion over $[\mathrm{Sn}, \mathrm{Al}]-\mathrm{Beta}(50)(\mathrm{Si} / \mathrm{Sn}$ molar ratio $=38, \mathrm{Si} / \mathrm{Al}$ molar ratio = 52). Reaction conditions: $10 \mathrm{wt} \%$ glucose solution $2 \mathrm{~mL}$, DMSO $6 \mathrm{~mL}$, $433 \mathrm{~K}, 4 \mathrm{~h}$.

reported.

Figure 8 shows the influence of the amount of $[\mathrm{Sn}, \mathrm{Al}]-\operatorname{Beta}(50)$ on the yield of 5 -HMF. When the amount of catalyst was greater than $50 \mathrm{mg}$, the yield of 5-HMF was constant. We also investigated the effect of the amounts of Sn and $\mathrm{Al}$ on the glucose conversion and 5-HMF/fructose selectivities. The results shown in Fig. 9(a) were obtained using the same amounts of Al. The reaction results are arranged in order of increasing Sn content, taking into account the fact that the two series of [Sn,Al]-Beta catalysts have different Sn contents. After reaction for $4 \mathrm{~h}$, even the $\mathrm{H}$-Al-Beta catalyst, which contained no Sn, gave a glucose conversion of $30 \%$. As the Sn content of [Sn,Al]-Beta increased, the glucose conversion increased, and reached nearly $60 \%$ when the $\mathrm{Si} / \mathrm{Sn}$ molar ratio was 35 . The 5 -HMF selectivity also increased, and reached nearly $62 \%$ at $\mathrm{Si} / \mathrm{Sn}$ molar ratio $=35$, whereas the fructose selectivity gradually decreased. However, all the increases or decreases were similar. The effects of the Al content, in the same range as that for the tests with Sn, are shown in Fig. 9(b). The glucose conversion increased gradually with increasing $\mathrm{Al}$ content, and the fructose selectivity decreased gradually. The 5-HMF selectivity
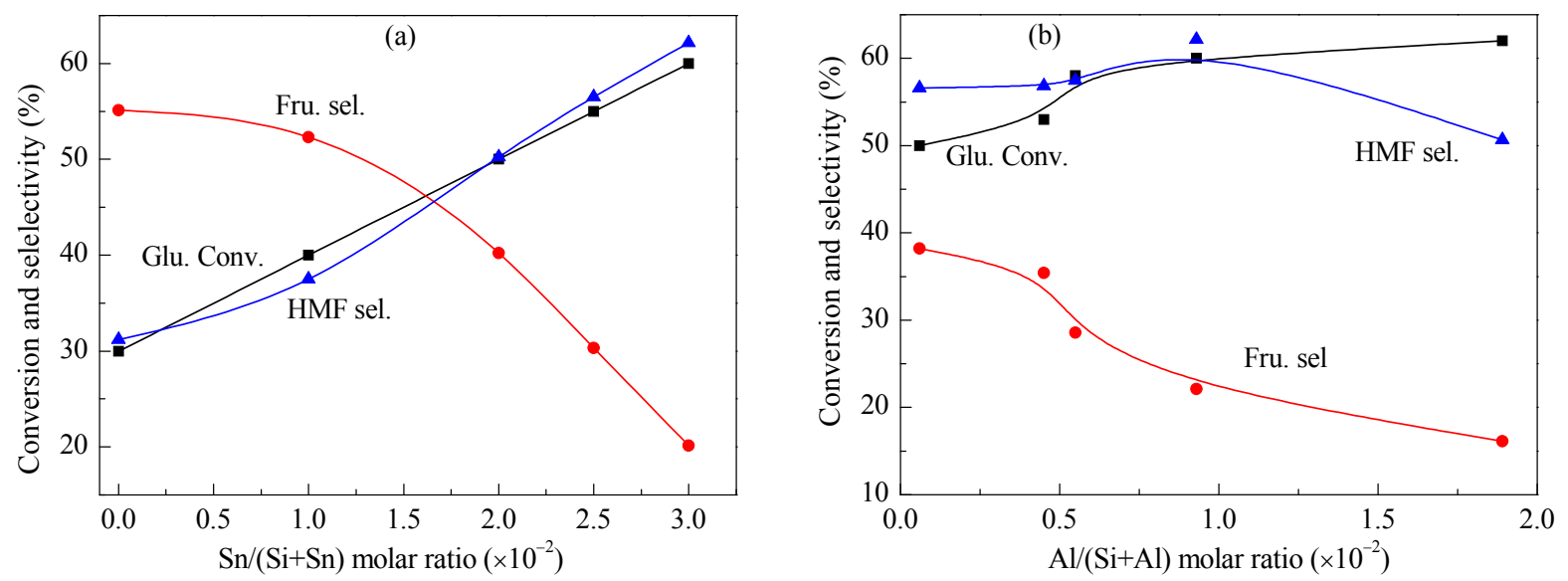

Fig. 9. Dependences of glucose conversion and product selectivity on Sn content (a) and Al content (b) in [Sn,Al]-Beta zeolites. Reaction conditions: catalyst $0.05 \mathrm{~g}, 10 \mathrm{wt} \%$ glucose solution $2 \mathrm{~mL}$, DMSO $6 \mathrm{~mL}, 433 \mathrm{~K}, 4 \mathrm{~h}$.

(a): De-Al-Beta(100) was treated with $\mathrm{SnCl}_{4}$ for $15 \mathrm{~min}$ to $1 \mathrm{~h}$ to obtain samples with various $\mathrm{Si} / \mathrm{Sn}$ molar ratios of 33-100.

(b): De-Al-Beta samples with different $\mathrm{Si} / \mathrm{Al}$ molar ratios $(50,99,174,215,1685)$ were treated with $\mathrm{SnCl}_{4}$ for $1 \mathrm{~h}$ to obtain comparable Si/Sn molar ratios of 33-37. 


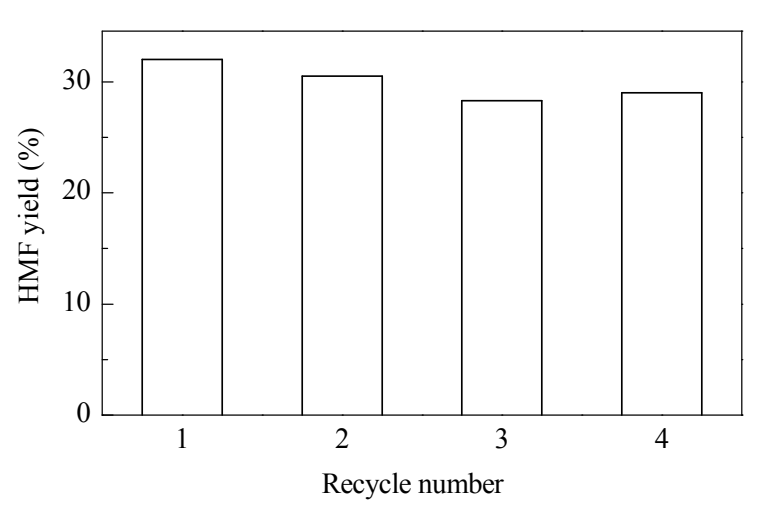

Fig. 10. Stability of yields of 5 -HMF in glucose conversion over $[\mathrm{Sn}, \mathrm{Al}]-\mathrm{Beta}(50)(\mathrm{Si} / \mathrm{Sn}$ molar ratio $=38, \mathrm{Si} / \mathrm{Al}$ molar ratio $=52)$. Reaction conditions: catalyst $0.05 \mathrm{~g}, 10 \mathrm{wt} \%$ glucose solution $2 \mathrm{~mL}$, solvent 6 $\mathrm{mL}, 433 \mathrm{~K}, 4 \mathrm{~h}$. After recycling three times, the catalyst was calcined at $823 \mathrm{~K}$ for $5 \mathrm{~h}$ to remove residual organic compounds.

first increased and then decreased with increasing $\mathrm{Al}$ content. When the Si/Al molar ratio of the parent Beta was 100 , we achieved the highest 5-HMF selectivity, $62 \%$. In the light of all the above data, it can be concluded that $\mathrm{Sn}$ ions are important for all the reactions, especially for the first aldose-ketose isomerization process, and relatively low amounts of $\mathrm{Al}$ catalyze the second dehydration process.

\subsection{Recyclability of [Sn,Al]-Beta}

Recyclability is important in catalytic applications. Figure 10 shows the recyclability of [Sn,Al]-Beta. The catalyst was evaluated in three repeated reactions; the activity dropped from $32 \%$ to $28 \%$. After calcination, the activity increased to $29 \%$, which was similar to that of the fresh catalyst. These results suggest that [Sn,Al]-Beta has excellent stability in glucose conversion to $5-\mathrm{HMF}$.

\section{Conclusions}

Nanocrystalline [Sn,Al]-Beta zeolites with high Sn contents can be prepared from partially dealuminated Beta-zeolites and
$\mathrm{SnCl}_{4}$ vapor using an atom-planting method. Unlike [Sn,Al]-Beta-L, which was synthesized by liquid-phase post-insertion of $\mathrm{Sn}$, the $\mathrm{Sn}$ ions are mainly incorporated into defect sites through the solid-gas reaction between $\mathrm{SnCl}_{4}$ and $\mathrm{SiOH}$ groups in hydroxyl nests. The nanosized [Sn,Al]-Beta catalysts have combined Lewis acidity ( $\mathrm{Sn}$ ions) and Brönsted acidity (Al ions), high Sn contents, and less diffusion limitations for bulky molecules, and are therefore active in the one-pot conversion of glucose to 5-HMF. This research suggests that more promising catalytic systems could be obtained by developing direct hydrothermal synthesis methods for nanosized $[\mathrm{Sn}, \mathrm{Al}]-$-Beta with high Sn loadings.

\section{References}

[1] Huber G W, Iborra S, Corma A. Chem Rev, 2006, 106: 4044

[2] Kunkes E L, Simonetti D A, West R M, Serrano-Ruiz J C, Gärtner C A, Dumesic J A. Science, 2008, 322: 417

[3] Bond J Q, Alonso D M, Wang D, West R M, Dumesic J A. Science, 2010, 327: 1110

[4] Vispute T P, Zhang H Y, Sanna A, Xiao R, Huber G W. Science, 2010, 330: 1222

[5] Savage N. Nature, 2011, 474:S9

[6] Chheda J N, Huber G W, Dumesic J A. Angew Chem Int Ed, 2007, 46: 7164

[7] Climent M J, Corma A, Iborra S. Green Chem, 2011, 13: 520

[8] Liu M, Jia S Y, Li C Z, Zhang A F, Song C S, Guo X W. Chin J catal (刘 民, 贾松岩, 李常增, 张安峰, 宋春山, 郭新闻), 2014, 35: 723

[9] Roman-Leshkov Y, Chheda J N, Dumesic J A. Science, 2006, 312: 1933

[10] Lin Y C, Huber G W. Energy Environ Sci, 2009, 2: 68

[11] Perego C, Bosetti A. Micropor Mesopor Mater, 2011, 144: 28

[12] Takagaki A, Ohara M, Nishimura S, Ebitani K. Chem Commun, 2009: 6276

[13] Zhao H B, Holladay J E, Brown H, Zhang Z C. Science, 2007, 316: 1597

[14] Huang R L, Qi W, Su R X, He Z M. Chem Commun, 2010, 46: 1115

[15] Otomo R, Yokoi T, Kondo J N, Tatsumi T. App Catal A, 2014, 470: 318

[16] Corma A, Nemeth L T, Renz M, Valencia S. Nature, 2001, 412: 423

[17] Corma A, Fornés V, Iborra S, Mifsud M, Renz M. J Catal, 2004, 221: 67

\section{Graphical Abstract}

Chin. J. Catal., 2015, 36: 820-828 doi: 10.1016/S1872-2067(14)60287-4

\section{One-pot synthesis of 5-hydroxymethylfurfural from glucose using bifunctional [Sn,Al]-Beta catalysts}

Liang Li, Jianghong Ding, Jin-Gang Jiang, Zhiguo Zhu, Peng Wu* East China Normal University

[Sn,Al]-Beta served as an integrated, bifunctional, and stable solid acid catalyst for the conversion of glucose to 5-hydroxymethylfurfural (5-HMF) in a continuous slurry reactor, giving $60 \%$ glucose conversion and $62 \% 5$-HMF selectivity.

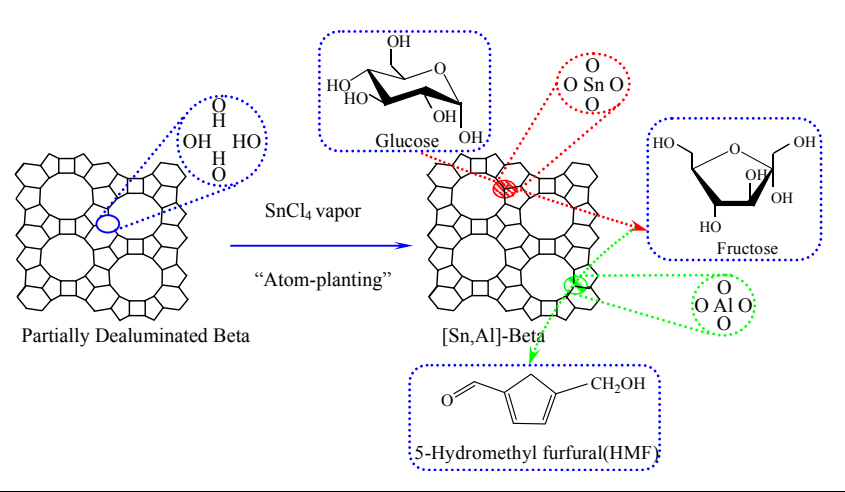


[18] Li P, Liu G Q, Wu H H, Liu Y M, Jiang J G, Wu P. J Phys Chem C, 2011, 115: 3663

[19] Zhu Y, Chuah G, Jaenicke S. J Catal, 2004, 227: 1

[20] Corma A, Domine M E, Nemeth L, Valencia S. J Am Chem Soc, 2002, 124: 3194

[21] Nikolla E, Roman-Leshkov Y, Moliner M, Davis M E. ACS Catal, 2011, 1: 408

[22] Velarde A M, Bartl P, Nießen T E W, Hoelderich W F. J Mol Catal A, 2000, 157: 225

[23] Hammond C, Conrad S, Hermans I. Angew Chem Int Ed, 2012, 51, 11736

[24] Dijkmans J, Gabriëls D, Dusselier M, de Clippel F, Vanelderen P, Houthoofd K, Malfilet A, Pontikes Y, Sels B F. Green Chem, 2013, 15, 2777

[25] Mal N K, Ramaswamy V, Ganapathy S, Ramaswamy A V. Appl Catal A, 1995, 125: 233

[26] Renz M, Blasco T, Corma A, Fornés V, Jensen R, Nemeth L. Chem
Eur J, 2002, 8: 4708

[27] Zecchina A, Spoto G, Bordiga S, Ferrero A, Petrini G, Leofanti G, Padovan M. Stud Surf Sci Catal, 1991, 69: 251

[28] Wu P, Komatsu T, Yashima T. J Phys Chem, 1995, 99: 10923

[29] Wu P, Komatsu T, Yashima T. J Phys Chem, 1996, 100: 10316

[30] Buzzoni B, Bordiga S, Ricchiardi G, Lamberti C, Zecchina A, Bellussi G. Langmuir, 1996, 12: 930

[31] Pazé C, Bordiga S, Lamberti C, Salvalaggio M, Zecchina A, Bellussi G. J Phys Chem B, 1997, 101: 4740

[32] Bonino F, Damin A, Bordiga S, Lamberti C, Zecchina A. Langmuir, 2003, 19: 2155

[33] Ngamcharussrivichai C, Wu P, Tatsumi T.J Catal, 2005, 235: 139

[34] Wang Y, Liu Y, Li X, Wu H, He M, Wu P.J Catal, 2009, 226: 258

[35] Szmant H H, Chundury D D. J Chem Technol Biotechnol, 1981, 31: 135

[36] Despax S, Estrine B, Hoffmann N, Le Bras J, Marinkovic S, Muzart J. Catal Commun, 2013, 39: 35

\title{
双功能[Sn,AI]-Beta分子篮一步催化葡萄糖生成5-羟甲基糠醛
}

\author{
李良，丁姜宏，蒋金刚，朱治国，吴 鹏* \\ 华东师范大学化学系上海市绿色化学与化工过程绿色化重点实验室, 上海200062
}

摘要: 以部分脱铝的Beta分子篮为母体, 采用同晶置换法将 $\mathrm{Sn}$ 植入骨架制备双功能 [Sn,Al]-Beta分子篮, 并应用于葡萄糖一步催化 生成5-羊全甲基糠醛(5-HMF)反应中. 样品中 $\mathrm{Sn}$ 与 $\mathrm{Al}$ 的含量通过酸洗的浓度和酸洗的时间以及 $\mathrm{SnCl}_{4}$ 处理的时间来控制. 由于骨架 中有与Al相关为B酸位, 和 $\mathrm{Sn}$ 相关的L酸位, [Sn,Al]-Beta可作为一种双功能的固体酸催化剂. 优化了 [Sn,Al]-Beta催化葡萄糖一步 催化生成 $5-\mathrm{HMF}$ 的反应参数, 在最优 $\mathrm{Sn} / \mathrm{Al}$ 比条件下, 葡萄糖转化率为 $60.0 \%, 5-\mathrm{HMF}$ 选择性为 $62.1 \%$.

关键词: [锡,铝]-Beta; 醛糖酮糖异构; 双功能催化; 羊甲基糠醛; 生物质; 同晶置换

收稿日期: 2014-11-28. 接受日期: 2015-1-13. 出版日期: 2015-06-20.

*通讯联系人. 电话/传真: (021)62232292; 电子信箱: pwu@chem.ecnu.edu.cn

基金来源：国家自然科学基金(21373089, U1162102); 教育部博士学科点专项科研基金(2012007613000); 国家科技支撑计划 (2012BAE05B02); 上海市重点学科建设项目资助(B409).

本文的英文电子版由Elsevier出版社在ScienceDirect上出版(http://www.sciencedirect.com/science/journal/18722067). 